\title{
PESQUISA EXPLORATÓRIA NO PONTO DE VENDA DE EMPRESAS MULTINACIONAIS SUPERMERCADISTAS DE RIBEIRÃO PRETO-SP
}

\author{
SALGADO JÚNIOR, Alexandre Pereira ${ }^{1}$ \\ PENEDO, Antonio Sergio Torres ${ }^{2}$ \\ PACAGNELLA JÚNIOR, Antônio Carlos ${ }^{3}$ \\ OLIVEIRA, Marcio Mattos Borges de ${ }^{4}$
}

\begin{abstract}
RESUMO: Com o aumento da competitividade empresarial surgem inovações que possam tornar os produtos mais bem aceitos pela sociedade. Uma das estratégias que tem se destacado, é a da imagem da empresa socioambientalmente responsável. Sendo assim, este artigo buscou identificar se a caracterização de produtos com o denominado "selo de responsabilidade sócioambiental" exerce algum tipo de influência no processo de decisão de compra dos consumidores finais no ponto de venda. Para isto, foi realiza uma pesquisa de caráter quantitativo, no ponto de venda de duas grandes redes varejistas, por meio de questionários, em uma amostra de 324 consumidores. Os resultados obtidos indicaram que os consumidores finais têm algum conhecimento sobre o tema responsabilidade socioambiental e uma parte já notou o selo. No entanto, a grande parcela destes, não consegue associá-lo a sua respectiva causa. Também verificou-se que embora considerem importante que as empresas sejam socioambientalmente responsáveis, não observam se os produtos possuem alguma coisa que caracterize este fato e poucos estão dispostos a pagar mais pela aquisição destes produtos. Aparentemente os resultados indicam que esta estratégia, abordada pelo chamado marketing socioambiental, não conseguiu surtir os efeitos almejados e novos desenvolvimentos estratégicos são necessários de modo a se atingir tais objetivos.
\end{abstract}

Palavras-Chave: Marketing sócio-ambiental. Comportamento do consumidor. Vendas no varejo.

\begin{abstract}
With the increase of the enterprise competitiveness innovations appear that can become the most accepted products for the society. One of the strategies that if have detached, is of the image of the socialenvironment responsible company. This article searched to identify if the characterization of products with the called "stamp of social-environment responsibility" exerts some type of influence in the process of purchase decision of the final consumers in the point of venda. For this, it was carries through a research of quantitative character, in the point of venda of two great retail nets, by means of questionnaires, in a sample of 324 consumers. The gotten results had indicated that final consumers have some knowledge on the subject social-environment responsibility and a part already noticed the stamp. However, the great parcel of these, does not obtain to associate its respective cause. Also it was verified that even so they consider important that the companies are socialenvironment responsible, they do not observe if the products possess some thing that characterizes this fact and few are made use to pay more for the acquisition of these products. Apparently the results indicate that this strategy, for the call social-environment marketing, did not obtain to get the desired effect and new strategically developments are necessary in order to reach such objectives.
\end{abstract}

Keywords: Social-environment marketing. Behavior of the consumer. Vendas in the retail.

\footnotetext{
1 Professor Doutor Da Faculdade De Economia, Administração E Contabilidade De Ribeirão Preto. Emai: asalgado@usp br

2 Professor Mestre Da Fundação Educacional De Ituverava. E-mail: penedo@usp.br

3 Professor Mestre Da Fundação Educacional De Ituverava.

4 Professor Doutor Da Faculdade De Economia, Administração E Contabilidade De Ribeirão Preto. Email: mmattos@usp br
}

Nucleus, v. 5. n. 1 , abr. 2008 


\section{INTRODUÇÃO}

A partir da crise dos anos 70, o processo de desenvolvimento que se desenrolou ao longo das décadas seguintes, determinou uma série de mudanças no campo econômico, social e cultural, gerando um forte impacto tanto na vida dos indivíduos como das instituições.

Segundo Freitas (1997), as mudanças na esfera da produção, do emprego e das políticas públicas, observadas neste período, impuseram grandes alterações tanto na sociedade em geral (aumento da expectativa de vida, mudança no padrão de consumo e crescimento demográfico), também na família (mulher no mercado de trabalho, instabilidade conjugal, problemas da adolescência) e no indivíduo, que é afetado por todas estas mudanças. Paralelamente a este processo, o papel desempenhado por instituições tradicionais como o Estado, a Família, a Religião também se altera, levando os indivíduos a um aumento de incerteza e ansiedade, gerando assim uma forte crise de identidade. Para a autora, este ambiente hostil e incerto tem levado os indivíduos a buscarem novas fontes de apoio, novos ideais e crenças a seguir e assim, num contexto onde as tradicionais instituições como o estado, a família, a religião vivem momentos de crise, a empresa passa a assumir papéis destas instituições como: o ideal de desenvolvimento econômico, o círculo social fraterno e até mesmo "a busca de um modelo que lhe permita restaurar a integridade".

Para Pretto; Sanches (2001), as empresas em assumindo uma imagem de eficiência e eficácia, passam a ser o paradigma da sociedade moderna, de maneira que as instituições tradicionais passam a tê-la como imagem-objetivo, semelhante aos casos de clubes de futebol, entidades assistenciais, universidades, igrejas, órgãos públicos e até partidos políticos. Desta forma, segundo os autores, é possível afirmar que a empresa passa a ser a depositária das crenças da sociedade e, assim, transformando-se numa espécie de "templo da sociedade moderna" e deste modo, a expectativa com relação às empresas passa a extrapolar o aspecto econômico da produção de bens e serviços, geração de renda e resultados financeiros; elas passam a ser o credo de uma sociedade fascinada pela produtividade e por resultados, tentam desempenhar um papel político e social muito mais amplo, pretendendo inclusive assumir bandeiras de interesse coletivo e características inerentes aos cidadãos. Assim, cada vez mais as empresas têm-se voltado para questões que envolvem o aspecto político-social e que vão além das considerações meramente econômicas. Elas dizem respeito à proteção do consumidor, controle da poluição, segurança e qualidade de produtos, assistência médica e social e defesa de grupos minoritários, entre muitas outras.

A declaração do Business Council for Sustainable Development, um conselho formado por 50 líderes empresariais mundiais que teve início em 1991, afirma que, pelo fato de o mundo estar caminhando para mercados globais, iniciativas privadas e desregulamentação, este novo contexto requer empresas aptas a assumir mais responsabilidades sociais, econômicas e ambientais na definição de sua estratégia de atuação. Coloca ainda a necessidade da expansão do conceito sobre o que são parceiros, incluindo não apenas empregados e acionistas, mas 
também fornecedores, consumidores, vizinhos, grupos de cidadãos e outros.

Segundo Bendell; Murphy (1997), as ONGs, os administradores e representantes da indústria freqüentemente compartilham estes mesmos conceitos, mesmo que suas posições oficiais possam ser diferentes. Isso equivale a dizer que um novo nível de entendimento parece estar surgindo entre empresas e defensores sociais e ambientais, ainda que este diálogo e suas implicações políticas subseqüentes sejam difíceis de ser administradas.

Neste trabalho será abordada a questão estratégica das organizações, relacionada à responsabilidade social, que atualmente está sendo explorada pelas empresas como um instrumento de diferenciação mercadológica chamado de Marketing Social. Assim, o objetivo central do estudo é avaliar junto a consumidores de estabelecimentos varejistas, o impacto desta nova forma de atuar das empresas.

\section{ESTRATÉGIA E RESPONSABILIDADE SOCIOAMBIENTAL}

Na definição da estratégia empresarial, na visão tradicional, a responsabilidade da empresa traduz-se na busca da maximização dos lucros e na minimização de custos, e a tomada de decisões pelos administradores não é influenciada significativamente pelos aspectos sociais e políticos que afetam o ambiente de negócios. Essa visão, que prevalecia antigamente e é originária de um ambiente estável e previsível, considerava que "o que é bom para a empresa é bom para a sociedade". Formou-se a partir daí um arcabouço de leis e regulamentações que têm como premissa dar sustentação para que as empresas atinjam seus objetivos econômicos, não criando entraves e permitindo aos administradores concentrarem-se apenas nos aspectos econômicos que digam respeito ao funcionamento da empresa de forma eficiente e eficaz, sem terem que se preocupar mais amplamente com o contexto sócio- político e ambiental. Modernamente considera-se que a linha de divisão entre a empresa e seu ambiente é mais vaga e ambígua, o que torna o cenário mais complexo. A empresa passa a ser vista como uma instituição sociopolítica, que reflete a mudança de ênfase do econômico para o socioambiental e tentando valorizar aspectos como cultura, qualidade de vida, relacionamento humano, realização pessoal, etc. (PRETTO; SANCHES, 2001).

As empresas tentam assumir um papel de maior influência sobre a sociedade e os indivíduos, buscam preencher carências individuais de reconhecimento e gratidão, oferecer identidade socioambiental e sentimento de filiação, desenvolver valores além da esfera profissional, produzindo um sistema simbólico, de como são e de como devem ser feitas as coisas, aumentando sua atratividade e conseguindo uma adesão completa das pessoas, desempenhando enfim um papel de "salvadoras da pátria", plantando-se portanto no centro do afetivo dos indivíduos. Por outro lado, deve ser considerado também que a sociedade está mais atenta ao comportamento ético das empresas, que reflete as ações do seu corpo de executivos. As novas leis e regulamentações têm forçado mudanças de estratégia, que são observadas atentamente pela sociedade e fortemente divulgadas pelos veículos de comunicação. Hoje em 
dia é muito fácil para uma empresa perder a credibilidade frente ao grande público em função de um comportamento ético inadequado ou da não assunção de suas responsabilidades frente à comunidade (FREITAS, 1997).

Segundo Engel et al (2001), vivemos um tempo em que o consumidor está muito mais consciente de seus direitos e do que acontece no mercado de uma forma geral e faz, a partir disso, escolhas mais estudadas, protegido, inclusive, por códigos legais mais modernos e abrangentes, e assim, qualquer ambiente de mercado de livre-empresa é construído sobre a premissa de que o lucro e o ganho material devem ser objetivados pelas empresas, com a ressalva de que haja um foco no interesse de longo prazo dos consumidores.

Muita controvérsia persiste sobre se é necessário ou apropriado o envolvimento das empresas com a responsabilidade socioambiental, embora muitas organizações estejam realizando essas atividades. O principal argumento a favor dessa idéia, em geral presentes na definição da missão de muitas empresas, é o que assume a premissa de que os negócios como um todo deve gerar benefícios para a sociedade e exercem um forte impacto na maneira como a sociedade existe. Uma vez que essa influência é tão forte, o ambiente de negócios tem a responsabilidade de ajudar a manter e desenvolver o bem-estar geral da sociedade. Somandose a isso, há o argumento de que os negócios deveriam assumir atividades de responsabilidade social porque, lucratividade e crescimento andam de mãos dadas com um tratamento responsável dos funcionários, dos clientes e da comunidade. Ou seja, assumir responsabilidade social seria um meio de buscar o aumento da lucratividade organizacional.

Segundo Weigand et al (1996), há uma série de instituições financeiras que operam investimentos orientados por princípios éticos e morais, que atendem principalmente a fundos de pensão, fundos de desenvolvimento comunitário, fundações e indivíduos e cujo número de participantes e magnitude dos investimentos têm crescido vertiginosamente. Assim, investidores socialmente responsáveis levam em conta as questões éticas e morais para a tomada de decisões no seu processo de investimento e buscam investir de forma consistente com seus próprios princípios morais. Estes portfólios normalmente operam segundo filtros de exclusão, que evitam o investimento em alguns tipos de empresas. As mais evitadas são as indústrias de tabaco, álcool, jogo e a de produção de armas. Existem também os critérios de cenários positivos, que elegem empresas que investem em direitos humanos, meio ambiente, relações humanas, relações com os funcionários e com os consumidores, qualidade do produto, direitos dos animais, diversidade e políticas relacionadas à família (educação, segurança, etc.).

Weigand et al (1996) salientam que segundo representantes do First Union National Bank Philadelphia, o futuro promete um considerável crescimento dos fundos socialmente orientados e os investidores socialmente responsáveis podem exercer uma pressão direta nas corporações de modo a melhorar sua performance em áreas específicas através da participação dos acionistas. Pelo fato de os fundos socialmente orientados estarem se tornando cada vez mais lucrativos, atraindo um número crescente de investidores (o que, em termos do mercado financeiro, possivelmente anuncia uma tendência consistente), esse exemplo leva a pensar que 
verdadeiramente uma mudança estrutural está ocorrendo. Os investidores, os consumidores e o público em geral estão "apostando" numa postura mais séria das empresas com relação à sociedade.

No Brasil, empresas como Natura, C\&A, Klabin, Magazine Luiza e outras estão "apostando" que ao associarem suas marcas a projetos sociais se aproximarão mais dos consumidores e funcionários. Afirmam que a marca é o maior patrimônio que uma empresa pode ter, e ela só se fortalece se houver um conceito amplo de responsabilidade social. Este é um pensamento que vem se generalizando dentro do mundo empresarial, como forma de melhorar a imagem junto a clientes e conseguir a adesão dos funcionários, imprimindo um caráter mais nobre aos objetivos da empresa. Outro indicador que reforça esta tendência é a inclusão, nos "Critérios de Excelência" do Prêmio Nacional da Qualidade, do item "Responsabilidade Pública e Cidadania", colocando que a liderança da organização deve enfatizar suas responsabilidades públicas e praticar a boa cidadania. A responsabilidade pública refere-se às expectativas básicas da organização quanto à ética nos negócios, atenção à saúde pública, segurança e proteção ambiental.

Portanto, a questão da Responsabilidade Socioambiental vem ganhando corpo e sendo considerada um parâmetro importante na definição da estratégia empresarial e como tal passou a receber destaque especial, funcionando inclusive como elemento de diferenciação mercadológica, cuja área de estudo passou a ser denominada de "Marketing Socioambiental".

\section{MARKETING SOCIAL E O AMBIENTAL}

Segundo Kotler; Roberto (1992), o termo marketing social apareceu pela primeira em 1971, para descrever o uso de princípios e técnicas de marketing para a promoção de uma causa, idéia ou comportamento social. Desde então, passou a significar uma tecnologia de gestão da mudança social, associada ao projeto, implantação e controle de programas voltados para o aumento da disposição de aceitação de uma idéia ou prática social em um ou mais grupos de adotantes escolhidos como alvo. Para os autores, marketing social é uma estratégia de mudança de comportamento, que combina os melhores elementos das abordagens tradicionais da mudança social num esquema integrado de planejamento e ação, além de aproveitar os avanços na tecnologia das comunicações e na capacidade do marketing.

Schiavo (2004), coloca que o marketing social é uma ferramenta democrática e eficiente, que aplica os princípios e instrumentos de marketing, criando e outorgando maior valor à proposta social. Assim, por meio dele, redescobre-se o consumidor através de um diálogo interativo, o que permite um processo de reflexão, participação e mudança social. Segundo o autor, os resultados são mensuráveis pelos seus efeitos e podem ser avaliadas por sua eficácia, eficiência e efetividade.

Segundo Valle (1995), gestão ambiental consiste em um conjunto de medidas e procedimentos bem definidos e adequadamente aplicados que visam reduzir e controlar 
os impactos introduzidos por um empreendimento sobre o meio ambiente. Harrington; knight (2001) complementam que a gestão ambiental ocorre quando a organização gerencia sistematicamente suas questões ambientais, integrando-as, freqüentemente, à administração global. Identificam-se nos aspectos ambientais e nos impactos de suas atividades, produtos e serviços; desenvolvem políticas, objetivos e metas para administrá-los; aloca os recursos necessários para uma implementação eficaz; mede e avalia o desempenho, além de rever e examinar suas atividades com vistas ao aperfeiçoamento.

A adoção de uma estratégia socioambiental é uma decisão política, que deve envolver toda a empresa a se comprometer com a aplicação de princípios e valores em toda a cadeia produtiva, minimizando riscos em cada etapa do processo produtivo. "Uma estratégia adequada é aquela que neutraliza ameaças e explora oportunidades, enquanto capitaliza as forças e evita ou repara as fraquezas" (BARNEY, 1997:27).

A preocupação com a questão ambiental nos países considerados de primeiro mundo é, portanto, uma realidade já há algum tempo. Nestes países existem diversos produtos industrializados que possuem um perfil de processamento, durante toda a sua cadeia de produção, que enfatiza a preocupação com as conseqüências sobre o meio ambiente e se utilizam deste argumento como estratégia de diferenciação do produto. É muito comum encontrar nas gôndolas de supermercados americanos e, sobretudo europeus, produtos de limpeza, higiene pessoal e alimentos industrializados ou in natura que ostentam selos de certificação que atestam serem eles ambientalmente seguros e menos agressivos ao meio ambiente (OTTMAN, 1995).

É extremamente importante definir quais são os valores e a missão da empresa, pois, afinal, é através deles que suas ações serão pautadas. A responsabilidade tem que fazer parte de todo o programa da empresa e não só de um pedaço de papel. É necessário que todos os integrantes da empresa possam partilhar destes valores estabelecidos.

Segundo Tachizawa (2002), o planejamento estratégico e ambiental de uma organização deve ser entendido como um processo cujo objetivo final é dotá-la de um instrumento de gestão estratégica, o plano estratégico ambiental de longo prazo, e que represente a súmula do conceito estratégico da empresa, servindo de orientação para a definição e o desenvolvimento dos planos e programas de curto e médio prazos, bem como permitindo a convergência de ações em torno de objetivos comuns.

As empresas estão descobrindo que o desenvolvimento de produtos e processos de manufatura ambientalmente saudáveis fornece oportunidades para melhorar a imagem corporativa, a marca, economizando dinheiro e satisfazendo as necessidades dos consumidores no sentido de manter uma alta qualidade de vida sem destruir o meio ambiente.

Segundo a Pesquisa do Milênio sobre Responsabilidade Social das Empresas, realizada pela Environics International em 1999, ao formar uma impressão sobre uma empresa, as pessoas em todo o mundo se baseiam mais em sua contribuição para causas sociais e sua relação com o meio ambiente do que na reputação da marca ou em questões financeiras. Metade da população de 23 países pesquisados atenta para a 
atuação social das empresas - um em cinco consumidores disse que voltou a comprar ou deixou de comprar de empresas por causa de sua atuação social, e quase o mesmo número pensava em fazer o mesmo. (GRAYSON; HODGES 2002).

Os benefícios da gestão socioambiental podem ser observados no quadro 1

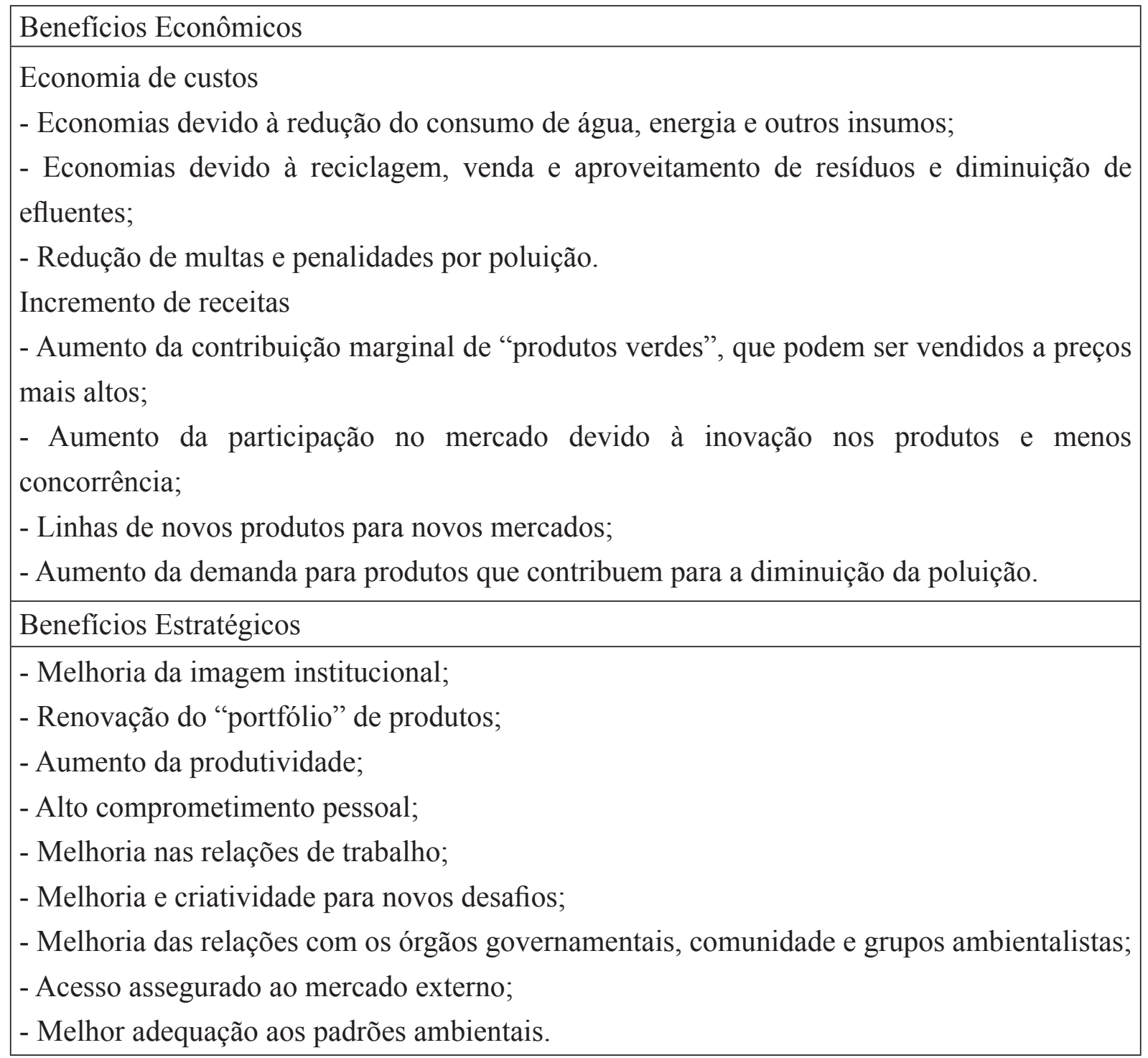

\section{Quadro 1: Benefícios da Gestão Socioambiental.}

Fonte: North, 1992, in Donaire, 1999 (adaptado).

Deste modo, nota-se que o marketing socioambiental está sendo utilizado atualmente como uma nova tecnologia na administração de empresas, sendo cada vez mais enfatizados pelas organizações para conseguirem se inserir em um mercado cada vez mais exigente. Por ser um termo novo, possui diversas abordagens, citadas acima, que por muitas vezes são utilizadas de diversas maneiras devido à sua complexidade de interpretação, porém, fica claro que as empresas começaram a se preparar e investir para conseguir atingir, de forma profissional, seus objetivos e as causas sociais nas áreas da saúde, educação e meio ambiente para desenvolver 
o bem comum, tendo em vista as transformações e a nova realidade social que vem ocorrendo em todo o mundo. Assim, esta nova maneira de encarar o desenvolvimento da estratégia empresarial, utilizando-se do marketing sociaoambiental, visa em última análise, influenciar no comportamento do consumidor de modo a gerar maiores benefícios para a sociedade e também para a organização.

Agestão socioambiental para as empresas brasileiras, principalmentepara as exportadoras, pode ser uma garantia de sobrevivência no mercado, uma vez que com a crescente importância aos produtos socialmente e ecologicamente corretos, a tendência dos fabricantes é encontrar atributos verdes em seus produtos como fator de diferenciação. Segundo Maimon (1994), os custos e os aspectos mercadológicos são, ainda, os fatores decisivos na mudança de estratégias, porém, é evidente que as empresas acreditam que o investimento na adoção de estratégias socioambientais poderá vir a aumentar o volume de seus negócios.

Neste sentido, Donaire (1999) diz que o retorno do investimento, antes, entendido simplesmente como lucro e enriquecimento de seus acionistas, ora em diante, passa, fundamentalmente, pela contribuição e criação de um mundo sustentável. Isto é corroborado por Souza (1993), ao dizer que as estratégias de marketing ecológico, adotadas pela maioria das empresas, visam a melhoria de imagem tanto da empresa quanto de seus produtos, através da criação de novos produtos verdes e de ações voltadas pela proteção ambiental. Desse modo, o gerenciamento socioambiental passa a ser um fator estratégico que a alta administração das organizações deve analisar.

\section{MODELO DE COMPORTAMENTO DO CONSUMIDOR}

Segundo Kotler (2000), o comportamento do consumidor descrito pelo modelo de estímulo e resposta (figura 1), ajuda a esclarecer o que acontece no consciente do comprador desde a recepção dos estímulos externos até a decisão de compra. Segundo o autor, o consumidor está sujeito a estímulos ambientais e de marketing que penetram no seu consciente. Dentre os estímulos ambientais têm-se as influências econômico-naturais, tecnológicas, político-legais e sócio-culturais que podem alterar a predisposição do consumidor a comprar ou rejeitar um produto ou serviço. Já os estímulos de marketing são os esforços empresariais empreendidos nas áreas de produto, preço, ponto e promoção para influenciarem nas decisões de compra do consumidor. Para Kotler; Armstrong (1999), todos esses estímulos entram na consciência do consumidor, onde são transformados em uma série de respostas como a escolha de produto, de marca, do revendedor, do momento e volume de compra. 


\begin{tabular}{|c|c|c|c|c|}
\hline $\begin{array}{c}\text { Estimulos } \\
\text { de }\end{array}$ & $\begin{array}{l}\text { Outros } \\
\text { Estimulo }\end{array}$ & $\begin{array}{c}\text { Característi } \\
\text { cas }\end{array}$ & $\begin{array}{c}\text { Processo de Decisão do } \\
\text { Comprador }\end{array}$ & $\begin{array}{l}\text { Decisóes do } \\
\text { Comprador }\end{array}$ \\
\hline $\begin{array}{l}\text { Marketing } \\
\text { Produto } \\
\text { Preço } \\
\text { Praça } \\
\text { Promoção }\end{array}$ & $\begin{array}{c}s \\
\text { Econônico } \\
\text { Tecrológico } \\
\text { Político } \\
\text { Cultural }\end{array}$ & $\begin{array}{c}\text { do } \\
\text { Comprador } \\
\text { Culturais } \\
\text { Sociais } \\
\text { Pessoais } \\
\text { Psicológicas }\end{array}$ & $\begin{array}{c}\text { Reconlecimerto de Problema } \\
\text { Busca de informações } \\
\text { A valiação de Altemativas } \\
\text { Decisão de Compra } \\
\text { Cormortamento após a cormra }\end{array}$ & $\begin{array}{c}\text { Escolha Produto } \\
\text { Escolha Marca e } \\
\text { do Revendedor } \\
\text { Frequîn niade } \\
\text { Compra } \\
\text { Momento de } \\
\text { C.nmmra }\end{array}$ \\
\hline
\end{tabular}

Figura 1: Modelo de estímulo e resposta.

Fonte: adaptado de Kotler (2000, p. 183)

No processo de decisão de compra do consumidor, resultam as decisões referentes a escolha do produto, escolha da marca, escolha do revendedor, freqüência de compra e montante de compra. Este processo varia conforme a responsabilidade pela decisão de compra (papéis), os tipos de decisão de compra e os passos no processo decisório de compra.

Segundo Sheth; Mittal; Newman (2001), este processo é composto de cinco etapas: a) reconhecimento do problema, b) busca de informação, c) avaliação de alternativas, d) compra e e) experiência pós-compra. Dependendo do tipo de envolvimento da compra, o consumidor pode avançar ou retroagir algumas etapas desse processo decisório. O processo decisório é iniciado quando um cliente reconhece um problema a ser resolvido ou uma necessidade a ser satisfeita. Um problema do cliente é qualquer estado de privação, desconforto ou falta (seja física ou psicológica) sentido por uma pessoa. O reconhecimento do problema é a percepção, pelo cliente, de que ele precisa comprar algo para voltar ao estado normal de conforto - em termos físicos ou psicológicos. Uma vez reconhecida a necessidade, os clientes buscam informações sobre vários modos alternativos de resolver o problema. Essa busca raramente inclui todas as marcas existentes. Em vez disso, os clientes consideram apenas um seleto subconjunto de marcas, que se organiza da seguinte forma: conjunto conhecido (marcas que o cliente conhece); conjunto evocado (marcas que o cliente lembra no momento de tomar a decisão); conjunto considerado (das marcas do conjunto evocado, as consideradas inadequadas são eliminadas, restando as que o cliente considerará comprar).

Para Kotler (2000), o processo de busca pode ser distinguido entre dois níveis de interesse; um estado de busca mais moderado, no qual a pessoa é mais receptiva a informações sobre um produto e no outro nível, em que existe uma busca ativa de informações, procurando a literatura a respeito, telefonando para amigos, visitando lojas para saber mais sobre o produto, entre outras. Ressalta-se aqui a importância das estratégias de comunicação da empresa, considerando as fontes de busca de informações dos consumidores.

Para Sheth; Mittal; Newman (2001), na avaliação de suas alternativas de escolha, o consumidor processa as informações e faz um julgamento de valor final baseando-se na sua racionalidade e consciência. Os processos e passos específicos são denominados pelos autores de "modelos de escolha" e dividem-se em duas categorias: os modelos compensatórios e não 
compensatórios. No modelo compensatório, o cliente chega a uma escolha considerando todos os atributos de um produto (ou benefícios de um serviço) e compensando mentalmente os pontos fracos em um ou mais atributos com os pontos fortes de outros atributos. Esse modelo é considerado compensatório porque uma falha em um atributo pode ser compensada por uma boa classificação em outro atributo. Já os modelos não compensatórios mais comuns são: a) modelo conjuntivo - o cliente começa determinando os limites mínimos de todos os atributos importantes, cada alternativa é então examinada para cada atributo, e qualquer uma delas que satisfaça os limites mínimos em todos os atributos pode ser potencialmente escolhida; b) modelo disjuntivo - implica compensações entre aspectos das alternativas de escolha. Difere do modelo compensatório, pois considera a simples presença ou ausência de atributos e compensa atributos que sirvam ao mesmo propósito, mas em tendência inversa; c) modelo lexicográfico - os atributos das alternativas são ordenados ou classificados em termos de importância, onde os clientes examinam todas as alternativas com base no critério mais importante e identificam aquela com o maior nível nesse critério; d) modelo de eliminação por aspectos (EPA) - é semelhante ao lexicográfico, mas com uma diferença importante, o cliente classifica os atributos em ordem de importância e, além disso, define valores de eliminação para realizar sua escolha.

Segundo Gutman; Alden (1985), Szybillo; Jacoby (1974), Zeithaml (1988), o consumidor seleciona, integra e avalia informações relacionadas aos produtos para chegar a um julgamento sobre as alternativas consideradas. Tais informações enquadram-se em duas categorias gerais de atributos; os extrínsecos, associam-se ao produto, mas não fazem parte da sua composição física, como o preço, a propaganda, a marca e a disposição no ponto de venda; e os intrínsecos, que incluem os componentes físicos e as características funcionais tais como design, cor, resistência, sabor e matérias-prima. Neste contexto, Zeithaml (1988), apresenta o modelo de meios e fim (Figura 2) integrando as concepções de qualidade, preço e valor, três componentes fundamentais (meios) das avaliações do consumidor que precedem a decisão de compra (fim). Assim, o consumidor encadeia as percepções e os julgamentos sobre a qualidade, o preço e o valor de uma oferta até chegar a uma decisão a respeito da compra. $\mathrm{Na}$ base da cadeia encontram-se os atributos extrínsecos e intrínsecos do produto e o preço. O modelo distingue entre preço objetivo e preço percebido. O primeiro é o preço expresso em padrão monetário. $\mathrm{O}$ segundo refere-se a um nível mais abstrato utilizado por alguns consumidores que podem não ter memorizado ou não lembrar o preço exato, mas mantêm um registro mental aproximado do nível de preço do produto, como sendo barato ou caro, por exemplo. Os três fatores, atributos internos, atributos externos e preço percebido combinam-se determinando a qualidade percebida, definida como a avaliação do consumidor sobre o nível de vantagem, excelência ou superioridade do produto. Além do preço percebido, a aquisição e o uso do produto geram outros custos de natureza não monetária, como tempo e esforço. Os dois tipos de preços, o monetário e o não monetário, combinam-se afetando a percepção do indivíduo sobre o nível de sacrifício que corresponde à compra e ao consumo.

No último estágio do modelo, o comprador estima o valor, cotejando o total dos benefícios 
que ele deverá proporcionar - em decorrência da qualidade percebida, de atributos extrínsecos e intrínsecos e de outros fatores geradores de benefícios, como conveniência e a gratificação - com a soma dos sacrifícios correspondentes. Repetindo esta avaliação para os diferentes itens incluídos no conjunto de alternativas consideradas para compra, a sua escolha deve recair sobre aquele produto com maior valor percebido.

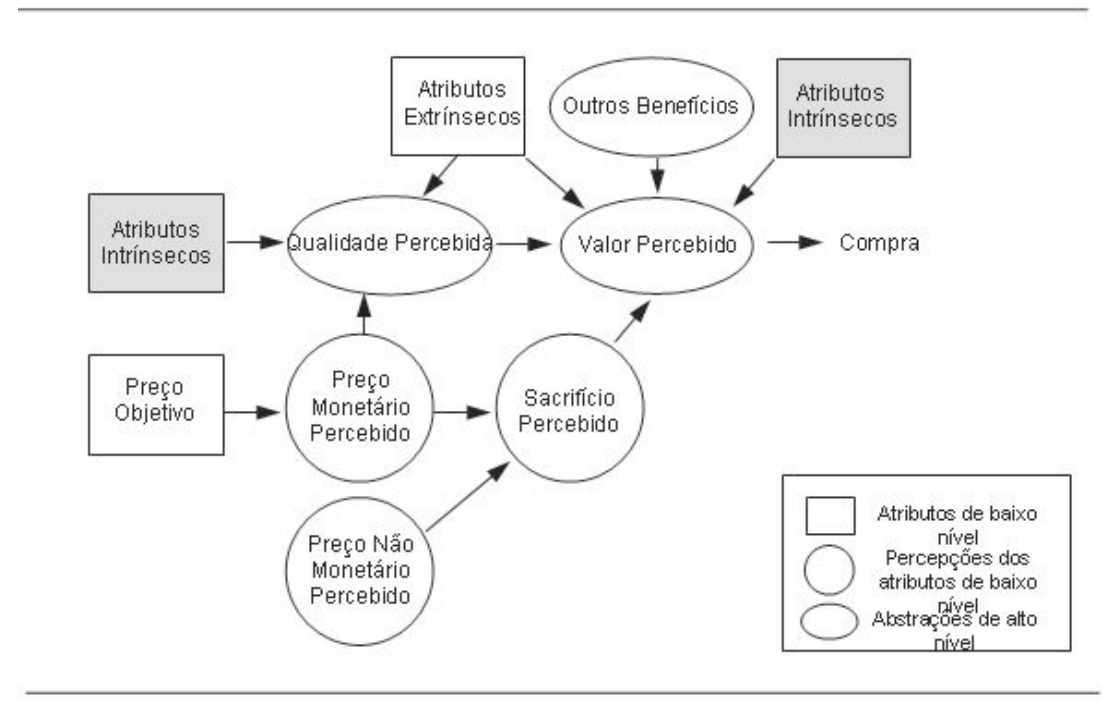

Figura 2: Preço, Qualidade e Valor: um modelo de meios e fim.

Fonte: Zeithaml (1988)

Em essência, o modelo informa que o processo de decisão de compra pode ser descrito como análises do consumidor sobre as características extrínsecas e intrínsecas de um produto ou serviço que o levam a formar percepções sobre os níveis de qualidade, preço e valor das diferentes alternativas incluídas no conjunto de produtos considerados para compra. É nessa capacidade de os atributos sugerirem ou predizerem para o comprador a presença de benefícios que deve ser o enfoque principal do marketing, pois não há como compreender as operações de compra do indivíduo sem explicar o papel dos atributos. Os atributos relevantes são aqueles que sinalizam, predizem ou geram benefícios importantes percebidos pelo consumidor.

Segundo Sheth; Mittal; Newman (2001), o processo decisório do cliente não termina com a compra pois, a experiência de comprar e usar o produto fornece informações que o cliente utilizará em uma tomada de decisão futura. Em alguns casos, o cliente ficará satisfeito com a experiência e comprará o mesmo produto do mesmo fornecedor de novo; em outros casos, o cliente ficará desapontado e poderá até devolver ou trocar o produto. Assim, segundo Kotler (2000), deve-se monitorar a satisfação, as ações e a utilização em relação ao produto depois de efetuada a compra.

A compreensão de todo o processo decisório do cliente é que permitirá desenvolver um programa de marketing para o mercado-alvo que seja consistente e eficiente e deste modo, todas as estratégias de comunicação e de posicionamento da oferta devem estar em consonância com esse processo decisório (KOTLER; ARMSTRONG, 1999). 


\section{A PESQUISA}

Com a finalidade de avaliar a influência da estratégia que vem sendo utilizada pelas empresas, chamada de marketing socioambiental, na decisão de compra dos consumidores finais foi realizada uma pesquisa de natureza quantitativa, conduzida por meio de questionários semi-estruturados nos pontos de venda de duas grandes redes multinacionais do setor varejista. Os questionários foram aplicados das 10 às 22 horas durante uma semana, objetivando-se obter amostras mais representativas da população. As empresas foram escolhidas pelo critério de conveniência por serem as mais representativas do setor de empresas multinacionais supermercadistas atuantes na cidade de Ribeirão Preto, sendo uma empresa do grupo francês Carrefour e a outra do grupo norte-americano Wall-Mart. Utilizou-se o selo da Associação Abrinq (empresa amiga da criança) e selos de caráter ambiental (como selo orgânico ou selo verde), como possível desenvolvimento de um marketing socioambiental e que implicaria em caracterização de uma empresa com responsabilidade social e/ou ambiental.

Para a aplicação do questionário as perguntas foram escalonadas objetivando-se tratálas estatisticamente, utilizando-se da escala Likert, que segundo Malhotra (2001), esta escala é definida como uma forma de mensuração com cinco categorias de respostas que vão de "discordo totalmente" a "concordo totalmente", e que exige que os participantes indiquem um grau de concordância ou de discordância de uma série de afirmações relacionadas com os objetivos de estímulo. As variáveis definidas foram:

- Grau de escolaridade;

- Conhecimento sobre o tema;

- Nível de preferência dos consumidores;

- Disposição de valorizar produtos;

- Importância de atributos.

Foi realizado um plano piloto, com a finalidade de verificar a eficiência das perguntas contidas no questionário, analisando se as mesmas são de compreensão dos respondentes; se as opções de respostas nas perguntas fechadas estão completas; se a seqüência está correta e calcular o tempo de aplicação. Serviu também para a obtenção de dados sobre o tipo de distribuição e para o cálculo do tamanho da amostra. Assim, foram aplicados inicialmente 104 roteiros de entrevista piloto, sendo $52 \mathrm{em}$ cada empresa. Os entrevistados foram escolhidos de forma aleatória e em períodos diferentes objetivando-se maior fidedignidade com a população.

A partir destes dados pode-se constatar que a distribuição das respostas acompanhava a curva normal (ou curva de Gauss) e calculou-se a média, a variância e o tamanho da amostra conforme as fórmulas abaixo:

$$
\bar{x}=\frac{\sum_{i=1}^{n}(\dot{x} \cdot f)}{(n-1)} \quad S^{2}=\frac{\sum_{i=1}^{n}(\bar{x}-\dot{x})^{2} \cdot f}{(n-1)} \quad n=\frac{\left(Z^{2} \cdot S^{2}\right)}{e^{2}} \quad \text { onde: }
$$

$\bar{x}=$ média, $f i=$ freqüência da resposta $i, x=$ valor da resposta $i, n=$ elementos da 
amostra,

$\mathrm{S}^{2}=$ variância, $Z=$ parâmetro da curva normal padronizada, $e=$ erro admitido.

Adotou-se erro de $5 \%$ e nível de confiança $90 \%$ que implica $Z=1,645$, conforme tabela de distribuição normal padronizada, chegando-se ao tamanho da amostra igual a 320 elementos.

\subsection{RESULTADOS DA PESQUISA}

Os dados a seguir são resultados obtidos por meio da aplicação dos questionários nos supermercados Carrefour e Wal Mart de Ribeirão Preto nos meses de Novembro e Dezembro de 2006. Inicialmente são apresentados os resultados de cada uma das perguntas do questionário e posteriormente serão feitas as análises com base nos dados obtidos.

Inicialmente deve-se destacar que, embora não intencional, o número de entrevistados do sexo masculino foi igual aos do sexo feminino.

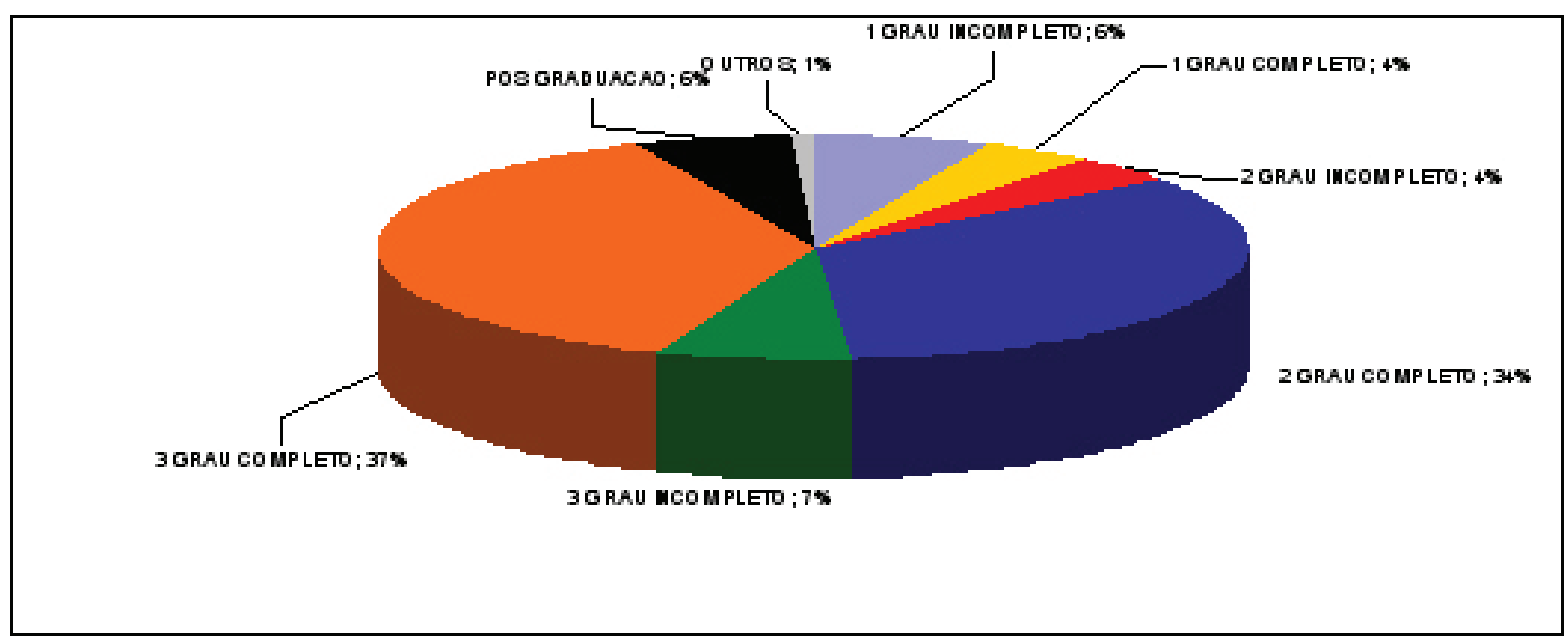

Gráfico 1: Nível de escolaridade.

O gráfico 2 representa a categorização do conhecimento sobre o tema responsabilidade socioambiental.

\section{Ouviu falar em responsabilidade socioambiental}

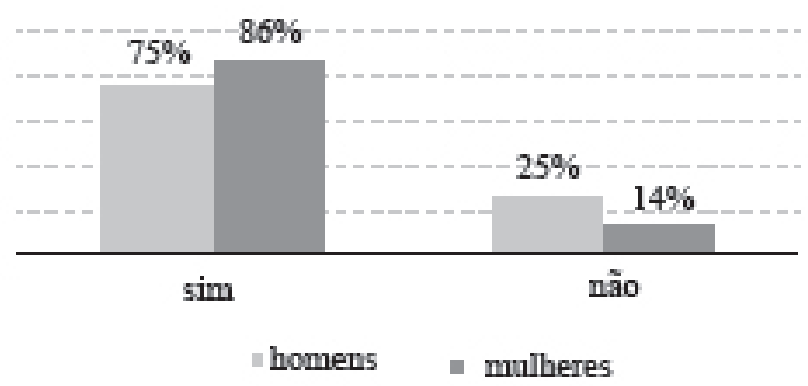

Gráfico 2: Conhecimento sobre o tema.

Ao ser apresentado selos de Responsabilidade socioambiental, foi perguntado se o 
entrevistado já tinha visto o mesmo. O gráfico 3 sintetiza as respostas dos pesquisados.

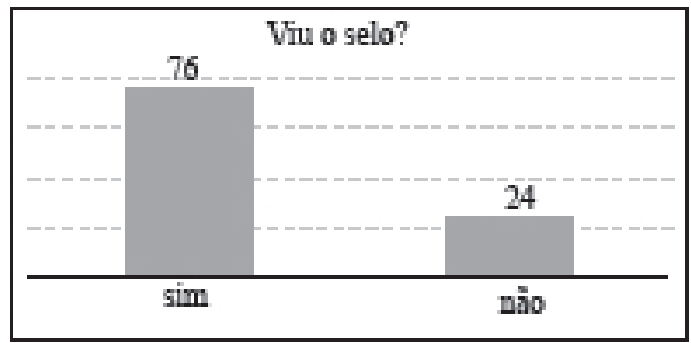

Gráfico 3: Conhecimento do selo de responsabilidade socioambiental.

Os gráfico 4, mostra a que os pesquisados associam o selo apresentado na pesquisa.

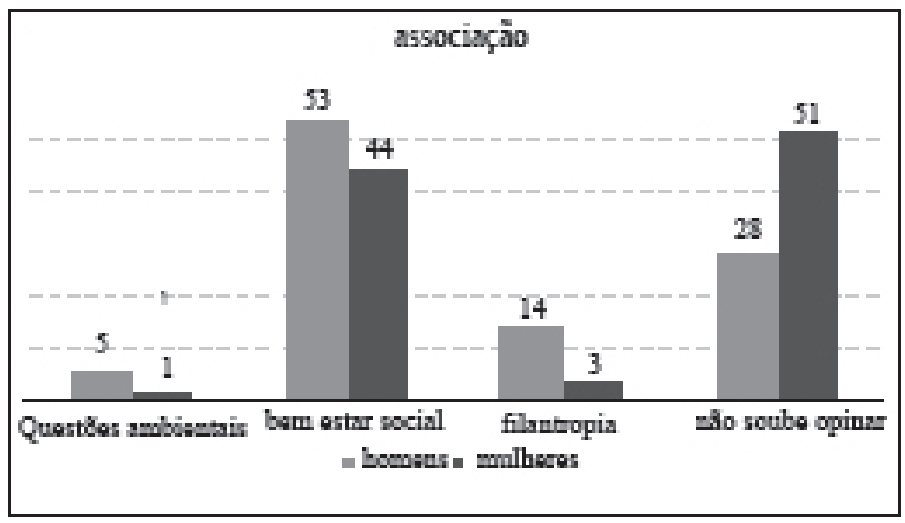

Gráfico 4: Associação do selo por sexo.

No gráfico 5 estão as respostas quando questionados se observam e dão preferência a produtos de empresas socioambientalmente responsáveis.

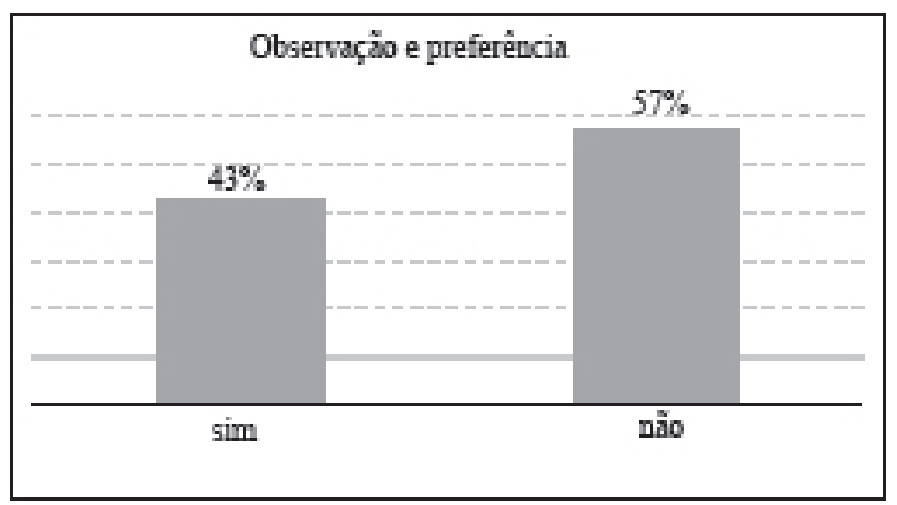

Gráfico 5: Observação e preferência por empresas socioambientalmente responsáveis.

O gráfico 6 mostra o percentual, dentre os respondentes que observam e dão preferência, que pagariam a mais por um produto de uma empresa socioambientalmente responsável. 


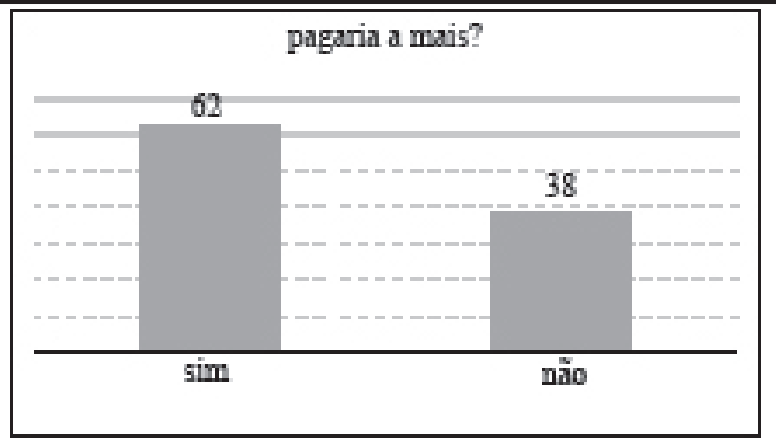

Gráfico 6: Pagaria a mais por produtos socialmente corretos.

O gráfico 7 mostra quanto estariam dispostos a pagar a mais, os que responderam afirmativamente a questão anterior.

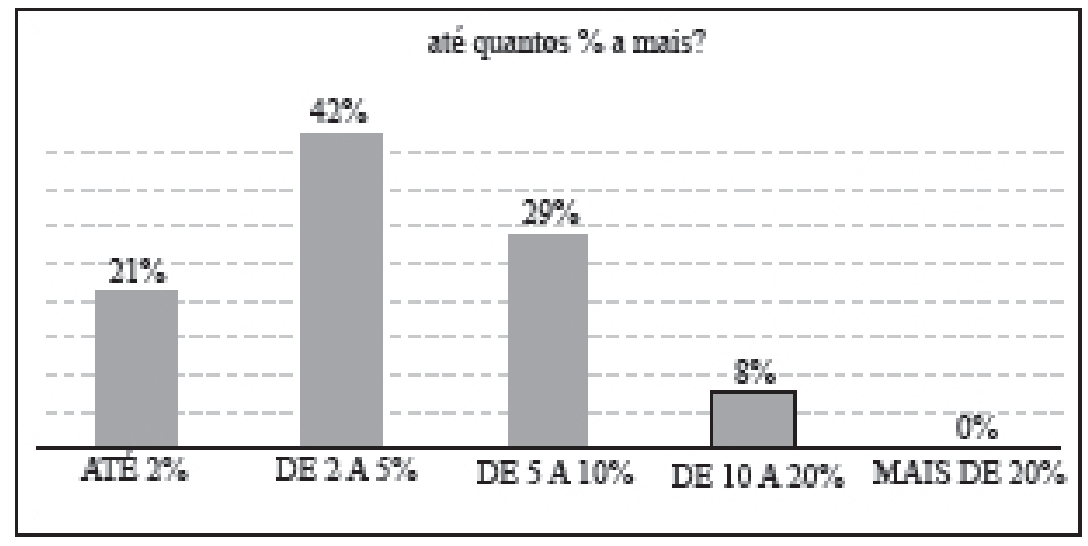

Gráfico 7: Percentual que estaria disposto a pagar a mais.

Na tabela 1 estão apresentados o grau de importância que os respondentes atribuíram a cada um dos atributos apresentados, sendo eles: preço, variedade, confiabilidade, produto de empresas com ações sociais e produtos de empresas ambientalmente corretas. A média apresentada foi calculada com base nos valores 1 -indiferente até 5-muito importante, ponderados de acordo com os valores percentuais apresentados para cada um destes valores dentro da escala.

Tabela 1: Importância dos atributos.

\begin{tabular}{|l|c|c|c|c|c|}
\hline ATRIBUTO & preço & variedade & confiabilidade & $\begin{array}{c}\text { ações } \\
\text { sociais }\end{array}$ & $\begin{array}{c}\text { ambientalmente } \\
\text { correta }\end{array}$ \\
\hline GRAU DE IMPORTÂNCIA & \multicolumn{5}{|c|}{$\%$ de respondentes } \\
\hline 1-indiferente & 4 & 4 & 1 & 18 & 22 \\
\hline & 5 & 4 & 2 & 10 & 10 \\
\hline & 25 & 29 & 7 & 19 & 12 \\
\hline 5-muito importante & 17 & 17 & 10 & 12 & 12 \\
\hline média & 49 & 46 & 80 & 41 & 44 \\
\hline
\end{tabular}

\subsection{ANÁLISE DOS RESULTADOS}


Dos resultados apresentados, deve-se salientar que, além da igualdade de respondentes entre os sexos masculino e feminino, a grande maioria tinha um razoável nível de instrução pois, $34 \%$ tinha o segundo grau completo, $44 \%$ tinha curso superior $(37 \%$ completo e $7 \%$ incompleto) e $6 \%$ com pós-graduação, totalizando $84 \%$ dos entrevistados. Sendo assim, era esperado que $81 \%$ ( $75 \%$ dos homens e $86 \%$ das mulheres - gráfico 2), já tivessem ouvido falar em responsabilidade socioambiental e que $76 \%$, já tinham visto o selo (gráfico 3).

Alguma surpresa é proporcionada quando se constata que aproximadamente 40\% (28\% de homens e $51 \%$ de mulheres - gráfico 4), não sabem nem opinar sobre a associação do selo com alguma coisa e também que 57\% não observam, nem dão preferência para produtos de empresas socioambientalmente corretas (gráfico 5).

Considerando que $43 \%$ observam e dão preferência aos produtos de empresas socioambientalmente corretas (gráfico 5) e que destes, $62 \%$ estariam dispostos a pagar mais por estes produtos (gráfico 6), pode-se dizer que aproximadamente $27 \%(0,43 \times 0,62)$ do total de entrevistados têm disposição de gastar mais por produtos desta natureza. Deste total, 63\% estariam dispostos a gastar no máximo $5 \%$ a mais $(21 \%$ até $2 \%$ a mais e $42 \%$ até $5 \%$ a mais gráfico 7). Isto implica em dizer que do total de entrevistados, $17 \%(0,27 \times 0,63)$ estaria disposto a gastar até $5 \%$ a mais na compra destes produtos, também aproximadamente $8 \%(0,27 \times 0,29)$ gastaria até $10 \%$ a mais e $2 \%(0,27 \times 0,08)$ gastaria entre 10 e $20 \%$ a mais na aquisição destes produtos.

Considerando estes resultados dentro do modelo de estímulo-resposta, pode-se notar que, por um lado está havendo estímulo de modo a influenciar alguma das características do consumidor (cultural, social, pessoal ou psicológica), pois já existe uma parcela significativa com algum conhecimento sobre o assunto, também existindo uma parcela, não tão significativa, mas que representam um importante indício de resultados positivos, pois levam em conta na avaliação de alternativas e decisão de compra as características de responsabilidade socioambiental, valorizando produtos de empresas com esta preocupação, observando, dando preferência e até pagando a mais por estes produtos. Por outro lado, nota-se que está havendo alguma falha no processo de comunicação das organizações e empresas relacionadas com o tema responsabilidade social, pois numa amostra em que $84 \%$ dos entrevistados tinham segundo grau completo ou mais, $40 \%$ sequer sabia relacionar isto com alguma característica apresentada e aproximadamente um quarto estariam dispostos a gastar alguma quantia adicional por esta característica ou atributo, sendo grande parte no máximo até 5\%; indicando que ainda não é muito valorizada esta forma de atuação das organizações.

Quando analisamos pelo modelo de meios e fins (preço, qualidade, valor), o resultado acima mostra que ainda existe pouco impacto no valor percebido pelo consumidor com relação a produtos com atributos relacionados a responsabilidade socioambiental, que podem ser intrínsecos, quando se trata de produtos que não agridem o meio ambiente, com embalagem reaproveitável, que não geram lixo e etc, ou extrínsecos, quando relacionados a empresas que revertem parte de sua renda em benefício da sociedade, por exemplo. A menor valorização 
destes atributos fica clara quando se observa a tabela 1, onde são apresentados três atributos tradicionais (preço, qualidade e confiabilidade) e dois atributos relacionados à responsabilidade social, empresa com ações sociais (extrínseco) e empresa ambientalmente correta (pode ser considerado intrínseco se diretamente relacionado ao produto). Na avaliação dos entrevistados, qualquer um dos dois atributos relacionados à responsabilidade socioambiental, quando comparados com os atributos tradicionais, se mostram de forma estatisticamente significativa, menos importantes para os consumidores.

Poderia ser questionado sobre a influência do grau de escolaridade sobre estes resultados, mas no estudo da correlação entre escolaridade e demais itens do questionário, verificou-se que este critério não possui nenhuma relação com os demais itens, uma vez que, o coeficiente de correlação em nenhum dos casos foi significativo.

\section{CONCLUSÃO}

As observações com os consumidores finais de empresas supermercadistas multinacionais de Ribeirão Preto - SP mostram indícios de que os mesmos conhecem o tema responsabilidade socioambiental e já notaram o selos do setor, no entanto, grande parcela destes, não consegue associá-lo a sua respectiva causa. Isto sugere a necessidade de um maior esclarecimento da importância da responsabilidade socioambiental, dado que no estudo observou-se algum grau de preferência e alguma relação entre dar importância ao tema e pagar mais por produtos de empresas socioambientalmente responsáveis. Sendo assim, considerando os conceitos de marketing socioambiental, seria interessante uma campanha informativa para que as empresas possam passar para os consumidores o verdadeiro significado de suas ações subentendidas nos selos apresentados nas embalagens. Destaca-se também que, de acordo com a pesquisa, o público feminino, em sua maioria, não soube opinar sobre a causa, e com isso, as organizações poderiam direcionar mais a comunicação para um público-alvo feminino.

Também verificou-se que apesar da maioria dos respondentes considerar os atributos da responsabilidade social e ambiental importantes, eles são significativamente menos valorizados que os atributos relacionados a preço, qualidade e confiabilidade, sendo que a maioria deles não leva isto em conta no momento da compra, não observando, nem dando preferência a estes produtos no momento da compra, sendo que uma parcela ainda baixa estaria disposta a pagar mais por este atributo. Novamente aqui, isto pode sugerir que os administradores do marketing socioambiental, precisam desenvolver e mostrar o real valor destes atributos que caracterizam os produtos de empresas que investem no setor.

Quando analisado o grau de escolaridade pode-se concluir, de acordo com os resultados apresentados, que ele não é um fator que diferencia a opinião dos entrevistados, pois não se achou nenhuma relação disto com as demais respostas. Com isso, percebe-se novamente a falta de conscientização sobre a responsabilidade socioambiental das empresas e a falha no processo de marketing socioambiental. 
Portanto, embora alguns resultados apresentem indícios positivos (ouvir falar do tema, disponibilidade de pagamento adicional), outros mostram claramente a necessidade de novos desenvolvimentos, tanto de produtos, como de comunicação e conscientização, para que o tema venha a ganhar mais corpo e seja significativamente valorizado da maneira como esperam as organizações e a sociedade em geral.

\section{REFERÊNCIAS}

BARNEY, J.B. Gaining and sustaining competitive advantage. Reading, MA: AddisonWesley, 1997.

CERTO, S.C. Modern Management. Boston: Allyn and Bacon, 1996.

CRITÉRIOS DE EXCELÊNCIA: o Estado da arte da gestão para a excelência do desempenho. 1997. (Manual da Fundação para o Prêmio Nacional da Qualidade.).

DACIN, P.A; BROWN, T.J. The company and the product: Corporate association and consumer product response. Journal of Marketing. v.61, n.1, p.68-84, 1997.

DONAIRE, Denis. Gestão ambiental na empresa. 2.ed. São Paulo: Atlas, 1999.

ENGEL, J.F.; BACKWELL, R.D.; MINIARD, P.W. Consumer Behavior. Forth Worth: The Dryden Press, 2001.

FONTES, M. (2004) Disponível em: <http://www.cidadefutura.com.br/observatoriodacidade /opiniao/artigos/artigo1_miguel_fontes.php > Acesso em: 10 de maio 2006.

FREITAS, M.E. Cultura Organizacional: sedução e carisma. 1997. Tese (Doutorado) - EAESP da Fundação Getúlio Vargas, São Paulo.

GUTMAN, J.; ALDEN, S.D. Adolescents' cognitive structures of retail stores and fashion consumption: a means-end chain analysis of quality. In: JACOBY, J.; OLSON, J.C. Perceived quality: how consumers view stores and merchandise. Lexington: Lexington Books, 1985.

HARRINGTON, H.J.; KNIGHT, A. A implementação da ISO 14000: como atualizar o SGA com eficácia. São Paulo: Atlas, 2001.

KOTLER, P. Administração de marketing: a edição do novo milênio. São Paulo: Prentice Hall, 2000 .

KOTLER, P. Marketing social. São Paulo: Atlas, 1999.

KOTLER, P.; ARMSTRONG, G. Princípios de marketing. São Paulo: Prentice Hall, 1999. 
KOTLER, P.; ROBERTO, E. Marketing social: estratégias para alterar o comportamento público. Rio de Janeiro: Campus, 1992.

KOZEL Jr., J. O Top do marketing brasileiro. São Paulo: Scipione, 1997.

MALHOTRA, N.K. Pesquisa de marketing: uma orientação aplicada. Porto Alegre: Bookman, 2001.

OTTMAN, J.A. Marketing verde. São Paulo: Makron BooKs, 1995.

PRETTO, F.N.; SANCHES, M.A.R. Empresa: o novo templo da sociedade moderna. Revista de Administração da Fundação Eurípedes, v.1, 2001.

SCHIAVO, M.R. (2004). Conceito de marketing social. Disponível em: $<\underline{\text { http://www.socialtec. }}$ com.br/>. Acesso em: 10 abr. 2005.

SCHIAVO, M.R. Conceito e evolução do marketing social. Conjuntura Social. v.1, n. 1 , p. 25-9, mai. 1999.

SHETH, J.N.; MITTAL, B.; NEWMAN, B.I. Comportamento do cliente: indo além do comportamento do consumidor. São Paulo: Atlas, 2001.

SOUZA, M.T.S. Rumo à prática empresarial sustentável. Revista de Administração de Empresas. São Paulo, n.33, v.4, p.40-52, jul./ago.1993.

SZYBILLO, G.J.; JACOBY, J. Intrinsic versus extrinsic cues as determinants of perceived product quality. Journal of Applied Psychology, v.59, p.74-78, 1974.

TACHIZAWA, T. Gestão ambiental e responsabilidade social. São Paulo: Atlas, 2002.

VALLE, C.E. Como se preparar para as normas ISO 14000: qualidade ambiental. São Paulo: Pioneira, 1995.

WASEK, G. Conceito \& Evolução do Marketing Social. Disponível em: http://www.socialtec. com.br>. Acesso em 13 de junho 2006.

WEIGAND, E.M.; BROWN, K.R.; WILHEM, E.M. Socially Principled Investing: caring about ethics and profitability. Trusts and Estates, aug. 1996.

ZEITHAML, V.A. Consumer perceptions of price, quality and value: a means-end model and synthesis of evidence. Journal of Marketing. Chicago, v.52, p.2-22, 1988.

Nucleus, v. 5. n. 1 , abr. 2008 